\title{
High Performance Manufacturing - An Innovative Contribution towards Industry 4.0
}

\author{
Odd Christian Sandengen \\ Arkitek AS - Innovation And Business Development \\ Kongsberg, Norway \\ ocs@arkitek.no
}

\author{
Leif A. Estensen, Harald Rødseth, and Per Schjølberg \\ Department of Production and Quality Engineering \\ NTNU \\ Trondheim, Norway \\ leif.a.estensen@ntnu.no, \\ harald.rodseth@ntnu.no, per.schjolberg@ntnu.no
}

\begin{abstract}
This abstract is an introduction to the next generation of High Performance Industrial Manufacturing, through the Industry standard 4.0. The fourth Industrial standard is based on advanced Automation and Robotics, sensor based computer technology, interconnected by wireless communication, and supported by BIG Data solutions. Effective management and human cooperation i.e. teamwork and SUM() processes will be increasingly important in the future. This paper also focuses on the new industrial standard in relation to $\mathrm{OEE}$ (Overall Equipment Effectiveness), Predictive Maintenance and total performance related to all equipment in the industrial factory processes. Not a few highly automated machines, but the system as whole. OEE is a well-known standardized tool for performance measurement throughout the industry. In order to utilize data systems as ERP (Enterprise Resource Planning) and PLM (engineering systems), they must be integrated with business systems. Management normally acts on the bases of facts and financial performance. In most companies increased profit is the overall goal. Future management systems aim for a fully integrated and automated data flow based on advanced sensor technology. Increased use of digital systems enables quicker and better decisions. Refers to previous paper "High Performance Innovative teams (IWAMA 2010).
\end{abstract}

Keywords- Process Management; High Performance Teams; Business Management Systems; Predictive Maintenance; OEE (Overall Equipment Effectiveness); Profit Loss Indicator (PLI)

\section{INTRODUCTION}

\section{A. Industry 4.0 and the Internet of Things (I4.0) \& (IoT)}

Industry 4.0 (I4.0) and The Internet of Things (IoT), address the same change. The Inter Connection between Equipment and Machines', and increasingly Automation level, but they have a different focus. A core element in this industrial revolution is the Cyber-Physical Systems (CPS) [8]. This is then considered as the technological result where almost everything in the physical world such as the machines are converged into the computing world in cyber space.

Industry 4.0 has a basic focus on the production process within a "smart factory". Highly automated and connected machines communicate with each other and also with the elements that they process, such as all kinds of components and resources, which are pre-produced and provisioned through a logistics chain.
The Internet of Things, on the other hand, does not have a focus on production, however on the utilization phase of digitalized and connected devices and products, which allows the vendors to communicate with their own products while they are used by the customers and to provide new "digital" customer services such as predictive maintenance.

Both also address the impact on other elements of the industrial value chain within a company such as research and development and sales and marketing. Both trends examine the possibilities arising through Inter Connection on various levels.

\section{B. Integration of Advanced Technology leading to High Performance}

Advanced technology is the foundation of Industry 4.0. Many different technologies are already used in manufacturing, but new solutions will transform production. Previous isolated and optimized cells will operate as fully integrated and automated production lines. This will lead to higher performance and greater efficiency. We will see a change in supply chains, producers, and customers. Changes in design or products will be communicated directly to the producers and read by communication systems, which updates all information in the production and logistics lines.

\section{Big Dato}

Analytics based on large data sets has entered the manufacturing world. This allows optimization and production quality, saves energy and improves equipment service. In an Industry 4.0 perspective, the collection and evaluation of data from many different sources will become standard to support real-time decision making.

\section{Future Robotics}

Manufacturers in many industries have introduced robots in order to reduce production time. New technology has made it possible to produce autonomous, flexible, and cooperative robots that communicate with one another. They will interact with one another and work safely side by side with humans. Robots are already cheaper, easier to program, lighter and thus more flexible in future productions lines. Sensors and control units enable close collaboration with humans. ABB has introduced a two-armed robot called YuMi that is specifically designed to assemble products alongside humans. 


\section{E. Simulation}

3-D simulations have already been introduced in production processes. In the future, simulations will be used more extensively in plant operations. This allows operators to test and optimize the machine setup for the next product in line in the virtual world before production startup. This reduces downtime due to setup loss and increase performance and quality.

\section{F. Horizontal and Vertical System Integration}

IT systems in different companies are seldom fully integrated, and suppliers are rarely linked with customers. Integration of value chains will open up for greater effectiveness both within engineering and production lines. When introducing Industry 4.0, companies and capabilities will become much more cohesive, and universal data integration networks evolve and enable truly automated value chains.

\section{G. The Industrial Internet of Things}

Today, only some of a manufacturer's sensors and machines are networked and make use of embedded computing. They are typically organized in a vertical automation pyramid in which sensors and field devices with limited intelligence and automation controllers feed into an overarching manufacturing process control system. But with the Industrial Internet of Things, more devices will be enriched with embedded computing and connected using standard technologies. This allows field devices to communicate and interact both with one another and with more centralized controllers.

\section{H. Cyber security}

Many companies still rely on management and production systems that are unconnected or closed. With the increased connectivity and use of standard communications protocols that come with Industry 4.0, the need to protect critical industrial systems and manufacturing lines from cyber-security threats increases dramatically. As a result, secure, reliable communications as well as sophisticated identity and access management of machines and users are essential.

\section{The cloud}

Companies are already using cloud-based software for some enterprise and analytics applications, but with Industry 4.0, more production will require increased data sharing. The performance of cloud technologies will improve, achieving almost real time updates.

\section{J. Additive Manufacturing}

Companies have just begun to adopt additive manufacturing, such as 3-D printing, which they use mostly to prototype and produce individual components. With Industry 4.0, these additive manufacturing methods will be widely used to produce small batches of customized products that offer construction advantages, such as complex, lightweight designs. High performance, decentralized additive manufacturing systems will reduce transport distances and stock on hand.

\section{K. Maintenance within Industry 4.0}

"Industrie 4.0" origins are from Germany and is regarded to be the fourth stage of industrialization and will secure the future of German manufacturing industry [8]. This industrialization is a digitalized evolution in manufacturing and can be illustrated in Figure 1 adapted from [8] and [19]. Before the end of 18th century, the manufacturing process was based on manually work.

From the end of 18th century, mechanical work was possible through e.g. steam engines, and from the beginning of 20th century, electricity enabled mass production with assembly lines were introduced. The electronics and automation was introduced in the beginning of the 1970s with implementation of PLCs in manufacturing. The fourth industrialization will establish a Cyber-Physical System and will in maintenance be important for further development of a predictive maintenance concept in the company.

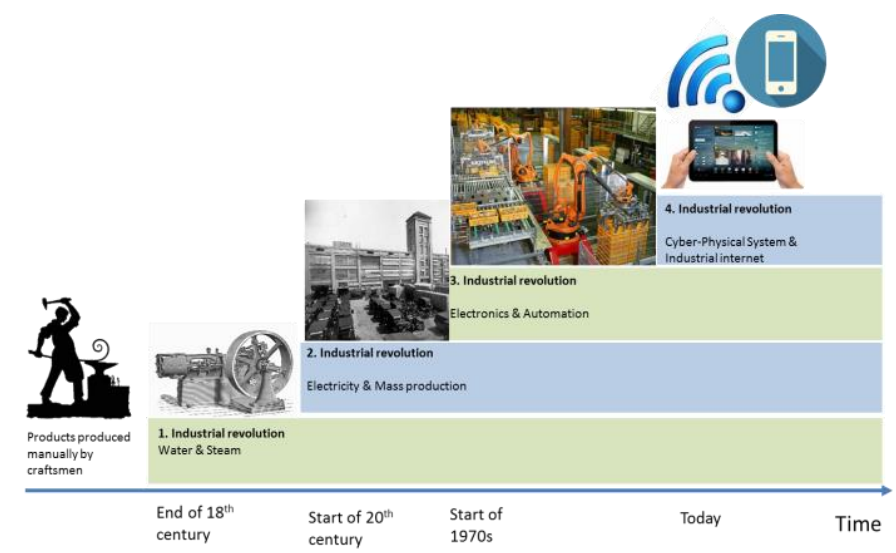

Fig. 1. The four stages of the Industrial Revolution adapted from [8] and [19].

A proposed definition of Industry 4.0 is as follows [20]:

"Industry 4.0 is a collective term for technologies and concepts of value chain organization."

Within this definition maintenance management should be included in the value chain organization. Table I elaborates the paradigm shift in manufacturing and maintenance where predictive maintenance should be an important element in Industry 4.0 with functionalities such as innovative visualization [19].

TABLE I. PARADIGM SHIFT IN MANUFACTURING AND MAINTENANCE [19].

\begin{tabular}{|c|c|c|}
\hline $\begin{array}{c}\text { Cost Focus } \\
>1980 \\
\end{array}$ & $\begin{array}{c}\text { Quality Focus } \\
\text { 1980-2010 } \\
\end{array}$ & $\begin{array}{c}\text { Customization Focus } \\
2010> \\
\end{array}$ \\
\hline Mass Production & Lean Production & Smart Manufacturing \\
\hline $\begin{array}{l}\text { Push policy } \\
\text { Motion \& time } \\
\text { study } \\
\text { Assembly line } \\
\text { Statistical sampling } \\
\text { Inventory } \\
\text { optimization } \\
\text { PERT/CPM } \\
\text { MRP }\end{array}$ & $\begin{array}{l}\text { Just-in time } \\
\text { Pull policy } \\
\text { Electronic data } \\
\text { interchange } \\
\text { TQM } \\
\text { Baldrige award } \\
\text { Kanban }\end{array}$ & $\begin{array}{l}\text { Economies of scope } \\
\text { Global manufacturing } \\
\text { Agile manufacturing } \\
\text { Internet-based manufacturing } \\
\text { Internet of Things } \\
\text { Data Analytics }\end{array}$ \\
\hline
\end{tabular}




\begin{tabular}{|l|l|l|}
\multicolumn{1}{|c|}{$\begin{array}{c}\text { Reactive } \\
\text { maintenance }\end{array}$} & \multicolumn{1}{|c|}{$\begin{array}{c}\text { Maturing } \\
\text { Maintenance }\end{array}$} & \multicolumn{1}{|c|}{ Predictive Maintenance } \\
\hline Corrective & Preventive & Proactive maintenance \\
maintenance & maintenance & LCP \\
Simple planning & Maintenance & Hidden factory \\
Simple analysis & budgeting & Asset Management \\
& CMMS \& KPIs & WCM \\
& TPM & Innovative visualization \\
& Root Cause & \\
& Analysis & \\
\hline
\end{tabular}

\section{PRedictive MaintenAnCE}

In Industry 4.0 it is regarded as an essential value driver to implement predictive maintenance in manufacturing. In fact, it is indicated by McKinsey \& Company that typical predictive maintenance can improve the asset utilization with 30 to $50 \%$ reduction of total machine downtime and increase the machine life with 20 to $40 \%$ [9]. In this paper, predictive maintenance is defined in accordance with the CEN-standard of maintenance terminology [10]:

"Condition based maintenance carried out following a forecast derived from repeated analysis or known characteristics and evaluation of the significant parameters of the degradation of the item."

In order to implement and align predictive maintenance into Industry 4.0, a sound and solid architecture for CPS is required. A proposed architecture for CPS is the 5C architecture and consists of 5 levels [11]. In Table 2 it is shown how predictive maintenance can be operationalized in CPS architecture.

Predictive maintenance is based on a combination of visual, automatic and dynamic information monitoring. Through sensor technology, performance information and operational data analysis it is possible to follow up on wear and repair, or corrective actions in order to obtain maximum performance through the machines lifetime. Predictive maintenance is closely connected to performance measurements, widely recognized as the industrial standard for Overall Equipment Effectiveness (OEE).

Predictive maintenance measures process efficiency through heat loss or nondestructive techniques, which can quantify the operating efficiency of non-mechanical plant equipment. Used in conjunction with vibration analysis it can provide maintenance managers and plant engineers with information that will enable them to achieve optimum reliability and availability. There are 5 main nondestructive techniques, like vibration monitoring, process parameter monitoring, thermography, tribology, and visual inspection.

Vibration monitoring normally provides the best tool for routine monitoring and identification of incipient problems. However, vibration analysis does not provide the data required on electrical equipment, areas of heat loss or condition of lubricating oil.
TABLE II. LEVELS OF CPS ARCHITECTURE AND RELATION TO PREDICTIVE MAINTENANCE [11].

\begin{tabular}{|l|l|}
\hline \multicolumn{1}{|c|}{ Level } & \multicolumn{1}{c|}{ Relation to predictive maintenance } \\
\hline $\begin{array}{l}\text { Level 1: } \\
\text { Smart } \\
\text { Connection } \\
\text { Level }\end{array}$ & $\begin{array}{l}\text { Real-time data acquisition from sensors in machines } \\
\text { and RFID from spare parts. In addition, the data is } \\
\text { transferred through wireless connection to local } \\
\text { servers. }\end{array}$ \\
\hline $\begin{array}{l}\text { Level 2: } \\
\text { Data-to- } \\
\text { Information } \\
\text { Conversion Level }\end{array}$ & Local computers near the machines runs algorithms. \\
\hline $\begin{array}{l}\text { Level 3: } \\
\text { Cyber Level }\end{array}$ & $\begin{array}{l}\text { Establishment of a mobile agent [5]. This will enable a } \\
\text { cloud of predictive maintenance where a collaborative } \\
\text { engineering team supports in prognosis and diagnosis } \\
\text { of the machines, as well as predictive maintenance } \\
\text { planning. }\end{array}$ \\
\hline $\begin{array}{l}\text { Level 4: } \\
\text { Cognition Level }\end{array}$ & $\begin{array}{l}\text { Visualization with dashboard through control room } \\
\text { and tablet technology. }\end{array}$ \\
\hline $\begin{array}{l}\text { Level 4: } \\
\text { Cognition Level }\end{array}$ & $\begin{array}{l}\text { Support from Cyber level with "digital advices" for } \\
\text { updating the maintenance plan. }\end{array}$ \\
\hline
\end{tabular}

Like preventive maintenance, predictive maintenance has many definitions. To some predictive maintenance is monitoring the vibration of rotating machinery in an attempt to detect incipient problems and to prevent catastrophic failure. To others, it is monitoring the infrared image of electrical switchgear, motors, and other electrical equipment to detect developing problems.

Predictive maintenance is a philosophy or attitude that, simply stated, uses the actual operating condition of plant equipment and systems to optimize total plant operation. Predictive maintenance is a condition-driven preventive maintenance program. Instead of relying on industrial or inplant average-life statistics (mean-time-to-failure) to schedule maintenance activities, predictive maintenance uses direct monitoring of the mechanical condition, system efficiency, and other indicators to determine the actual mean-time-to-failure or loss of efficiency for each machine and system in the plant. Traditional time-driven methods provide a guideline to "normal" machine life spans.

A predictive maintenance program provides facts on the actual mechanical condition of each machine and the operating efficiency of the manufacturing processes. The program can also identify machine problems before they become serious. Most mechanical problems can be minimized if they are detected and repaired early. Normal mechanical failure modes degrade at a speed directly proportional to their severity. Over the past years, a variety of Management methods, such as Total Productive Maintenance (TPM) and reliability-centered maintenance (RCM), have been developed for ineffective maintenance. Many domestic plants have partially adopted one of these Quick - fixes.

The Japanese approach to effective maintenance management was TPM - Total Productive Maintenance; developed by Deming in the early fifties (1951). His concepts, as adapted by the Japanese, stress absolute adherence to the 
basics, such as lubrication, visual inspections, and universal use of best practices in all aspects of maintenance.

TPM is not a maintenance management program. Most of the activities associated with the Japanese management approach are directed at the production function and assume that maintenance will provide the basic tasks required to maintain critical production assets. All of the quantifiable benefits of TPM are couched in terms of capacity, product quality, and total production cost.

At the core of TPM is a new partnership among the manufacturing or production people, maintenance, engineering, and technical services to improve what is called overall equipment effectiveness (OEE).

Predictive maintenance means improving productivity, product quality, and overall effectiveness (OEE) in manufacturing plants. Predictive maintenance uses vibration monitoring, thermal imaging, lubricating oil analysis or nondestructive testing techniques.

TPM pillars:

- Improving Equipment Effectiveness. Finding the six big losses and what causes the equipment to be ineffective. Making improvements continuously.

- Involving operators in daily maintenance.

- Improving maintenance efficiency and effectiveness.

- $\quad$ Educating and training personnel.

- Design and manage preventive maintenance.

To be able to compete for the national TPM prize in Japan, equipment effectiveness must be greater than $85 \%$. Equipment effectiveness in most companies barely reaches $50 \%$. No wonder that there is so much room for improvement in typical equipment maintenance management programs.

\section{HIGH PERFORMANCE, SUM@ AND PLI}

\section{A. High Performance through involvement, cooperation and communication - SUM ${ }^{\mathrm{TM}}$}

A SUM@ process is defined as - Strategic development and improvement, through collaboration and involvement of team members. How can we work effectively together? With focus on improvement processes, which involve people with different skills, experience and personalities. We have all attended team work in one way or another. Some of our discussions are probably relevant for many situations, however we bring in the aspect of time line and business focus.

Management wants to see result in shortest possible time frame. This adds a pressure to the production process, as results must be delivered in a given time. Normally this is generated from customer's needs and demands.

Many improvement processes sails under different flags. The LEAN-concept is one. [1] Problem Solving Techniques, 5S, Kaizen and Teambuilding are elements in these processes as well. Team development or "teambuilding" is often a "get together" where a certain project is "rolled out". Our impression is that "team development" is given low priority from the management in such processes. The reasons may be many, but we anticipate that team development is normally not a business manager's primary concern. Many seem to think that team development is too time consuming or already knows the competence in their business. Our experience is different, most leaders and team member needs training in order to be effective. Generally, we can say that without consideration for high performance, we will not reach our goals. Teamwork in a Pit Stop could be a good picture for "High Performance". We must define clear goals, define task and timelines, and organize the work as a minimum.

Even if innovation and improvement process are difficult to plan in detail, it is important to design for change and flexibility. Our experience shows clearly that we need to delegate decisions to the people close to the processes in order to work effectively.

The SUM ${ }^{\mathrm{TM}}$ concept shown in Figure 2 is based on a dynamic process of continuous improvement. We seek to improve existing solutions by developing better performance or results in every process or product in the value chain. This process can often lead to new and innovative ways to solve problems or challenges. $[2,3,4]$

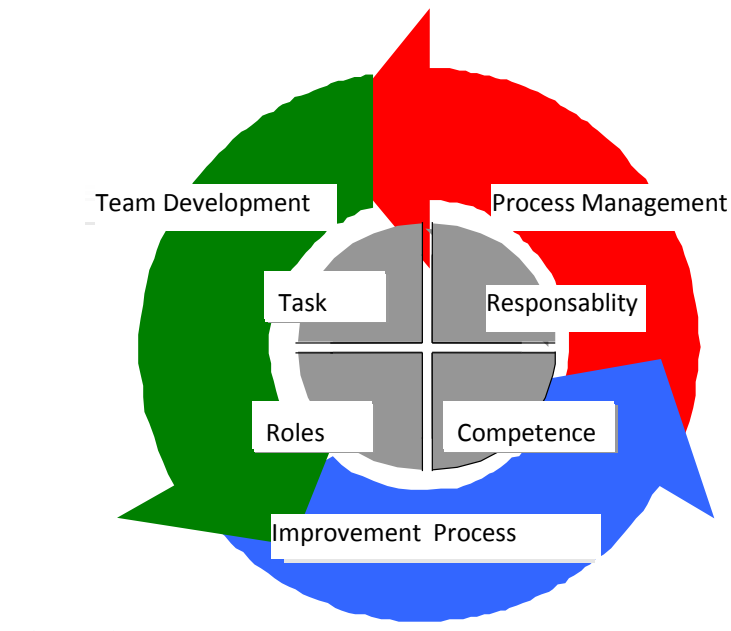

Fig. 2. The SUM@ Concept

\section{B. SUM@ Workshop Performance - Get Organized!}

A SUM(C) process require clear goals, defined task and timelines, effective work organizing - as a minimum. Even if innovation and improvement process are difficult to plan in detail, it is important to design for change and flexibility. The SUM $\odot$ Concept has been used in many organizations in connection with improvement processes in the whole value chain. In such processes these elements are important.

\section{High Performance Maintenance Process - The "Pit Stop" example}

In light of this we need to discuss Team Development and Team Performance. We have introduced the expression High Performance Teams. Generally, we can state the fact that both management and team members will benefit from attending training processes. Most teams also need a process-oriented 
leader in order to facilitate the process and remove obstacles that reduce team performance. Working together is a learning process. Through learning we can improve the output continuously and create high performance teams. This is an exciting and very energetic way of increasing the human capital through competence development. [5]

\section{High Performance Improvement}

In order to achieve better results, we need indicators to measure progress and improvements. Performance also relate to the reduction of time loss and Waste in the critical path of main processes. We need to innovate $\Rightarrow$ Develop $\Rightarrow$ and Improve - in order to obtain a continuous circle of process improvements:

- $\quad$ Select the right team member for the job

(Jim Collins - From Good to Great)

- $\quad$ Process measurements (dialog and evaluation)

- $\quad$ Process management skills (5S, SMED)

- Loss reduction

- $\quad$ Organize work and define team roles

- Release team power (energetic teams)

- Create a team culture

Working effectively together in a team means we have to develop good communication skills. We have to establish good working methods and define tasks and roles for each team member. Without measurement, we do not know where we are, and certainly not where to go i.e. - the next step in the improvement process. When we have defined what to measure and how to do it - we can log every event throughout the day or working shift. For instance, available time, loss related to unproductive work. When we remove these time consumers, we are left with the actual available time for work. This is one example of an engineer's working day, or a manufacturing machines available time for productive work during the shift.

\section{E. High Performance Manufacturing - Introduction to OEE}

Overall Equipment Efficiency (OEE) was defined and developed by Toyota in order to measure just how effective manufacturing processes were (Figure 2). Today OEE has become a standard for reporting business performance to management and business owners. [6]

- $\quad$ OEE-model (Figure 3) calculates the output for a machine or production line. In this way we have historical data.

- $\quad$ OEE-output measures 3 different components in \%:

\section{Availability \\ 2. Performance \\ 3. Quality}

The OEE-factor is the multiplication of these three factors. As a result, we will also find data for downtime and problems.
- Toyota has the highest OEE output in the world, with an OEE-factor at $90 \%$. In Europa OEE average was around $42 \%$ in early 2000 s.

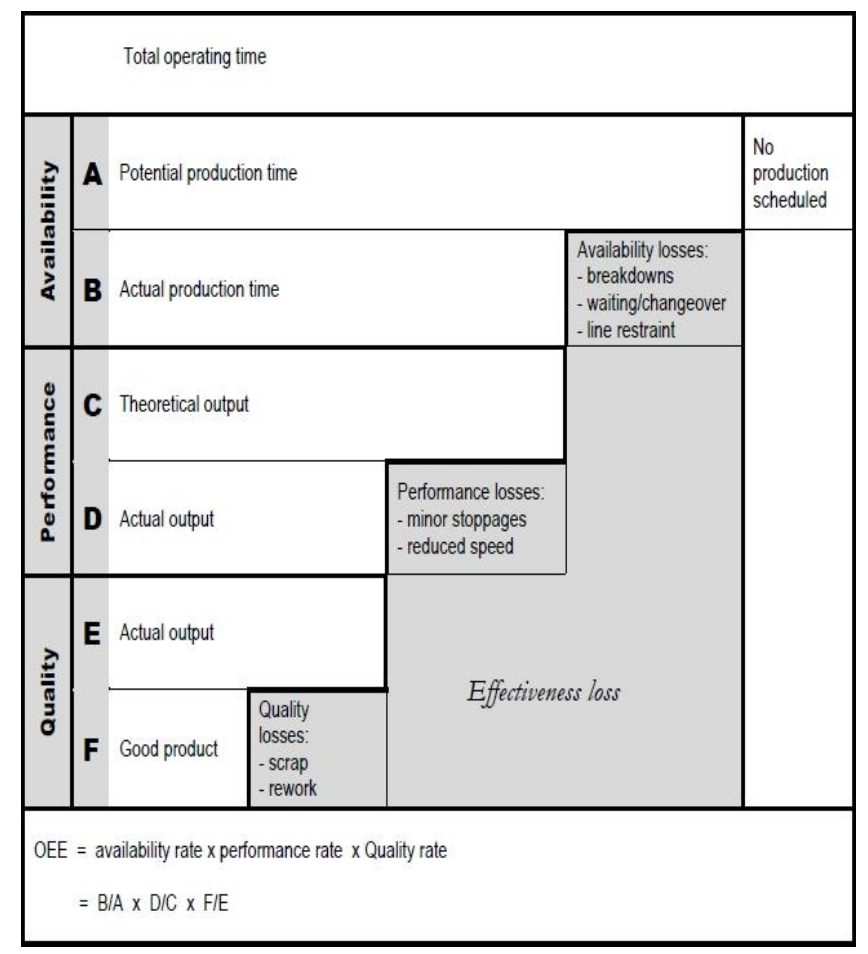

Fig. 3. The OEE - Model

\section{F. OEE Calculation}

The basis of the OEE calculation is:

(1) Availability: This portion of the OEE metric represents the percentage of scheduled time that the operation is available to operate. It is often referred to as uptime. Availability $=$ Available Time $/$ Scheduled Time

(2) Performance: This portion of the OEE represents the speed at which the work center runs as a percentage of its designed speed. Performance $=$ Actual Rate/Theoretical Rate

(3) Quality: This portion of the OEE metric represents the good units produced as a percentage of the total units started (commonly referred to as first-pass yield). Quality = Good Units/Units Started

(4) Example: A Manufacturing Company's plant is scheduled to operate for 16 hours (960 minutes) per day, five days per week, 50 weeks per year. Last year, the plant produced an average of 480 units per day, of which 460 met the quality specifications. The plant also averaged one product changeover per day at 30 minutes per change and experienced an average of 100 minutes per day of unplanned downtime. The plant was designed to produce 40 units per hour.

- Availability: Scheduled Time $=960$ minutes per day. Available Time $=960$ minutes scheduled $(100$ minutes unscheduled downtime +30 minutes' changeover) $=830$ minutes/day. Availability $=830$ available minutes divided with 960 scheduled minutes $=0,865$ 
- Performance: Actual Rate $=460$ units $/ 480$ units $=$ 0,93

- Quality $=460$ good units/480 units started $=0,94$

- $\mathrm{OEE}=$ Availability $\mathrm{x}$ Performance $\mathrm{x}$ Quality

- $\mathrm{OEE}=0,86.5 \times 0,93 \times 0,94=0,74 \Rightarrow 74 \%$

(5) World Class Manufacturing: Normally, less than $65 \%$ should be considered unacceptable, since it represents a very low competitiveness and a great number of economic losses. A value between 65 and $75 \%$ is considered as regular, only acceptable if it is being improved. A value between 75 and 85 $\%$ means an acceptable level with slight economic losses and which can be easily improved to World Class levels. A value between 85 and $95 \%$ is considered as good and equals World Class values; it represents a high level of competitiveness. And finally, a value above $95 \%$ is considered as excellence.

\section{G. Profit Loss Indicator (PLI)}

A step further of OEE is to have a monetary indicator where the hidden factory is measured. Profit Loss Indicator (PLI) has this functionality and is structured as a PLI cube shown in Figure 4. PLI is measured with a monetary unit such as USD and ranges from zero and upwards.

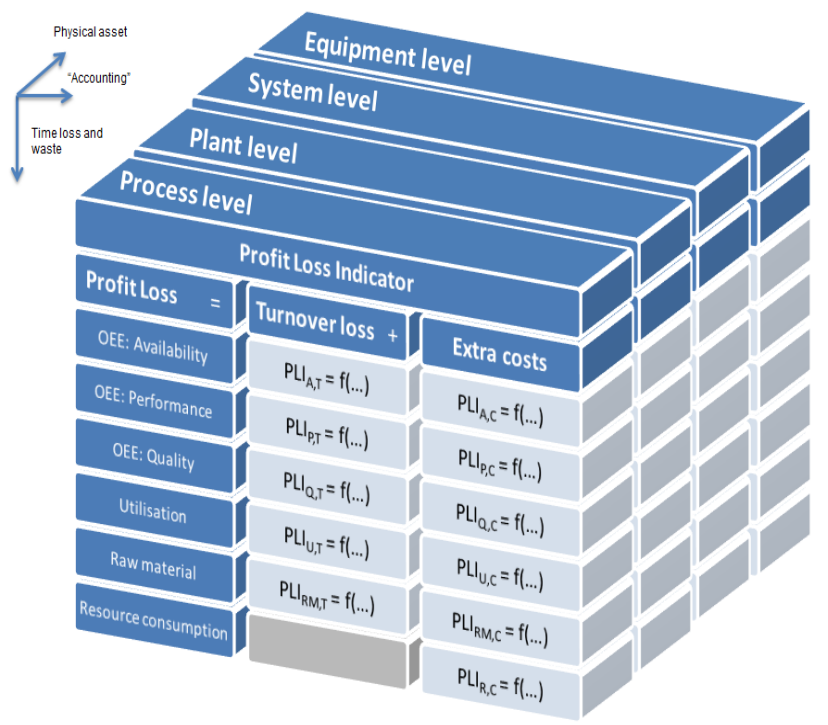

Fig. 4. PLI cube [18]

As shown in Figure 4, PLI can be structured in three dimensions:

- Physical asset: PLI is measured from equipment level up to plant level

- Accounting: In PLI it is always possible to see which elements contribute to turnover loss and extra costs

- Time loss and waste: From the hidden factory taxonomy, it is possible to trace the different time loss and waste categories

\section{PRINCIPLES OF QUALITY MANAGEMENT - FROM GREAT TO EXCELLENT}

Any business needs customers. Without customers, there is no business. Total Quality Management indicates that every business should exceed the customer needs and demands. Refers to section 0.1 in ISO9004: 2000.

Principle no. 1: Customer needs. Any business is dependent of their customers, and must try to understand their present and future needs, deliver according to specification and try to exceed their expectations.

Principle no. 2: Management responsibility. Management defines mission and strategy for the business. Management also creates and maintains a culture for involvement that makes it possible to reach business goals.

Principle no. 3: Involvement. Involvement makes it possible for employees to contribute with their competence. It also motivates each and everyone in the organization. Refers to section 4.1 in ISO9001: 2000. Continuous improvement cannot be fulfilled without involvement.

Principle no. 4: Process orientation. Process orientation is based on process thinking, and interactions between task and activities. In this perspective, process management is based on discussion and constructive interaction between people. This management style is different from the decision maker who tends to give orders and define certain ways of solving a given task.

Principle no. 5: Process Management. Managing processes means to identify, understand and control processes that interact as a system, in order to achieve business goals.

Principle no. 6: Continuous Improvement. Continuous Improvement should be a part of business strategy and include the whole organization.

Principle no. 7: Decisions based on facts. Effective decisions are based on analysis of information and fact-based data.

Principle no. 8: Partner based vendor relations. All business depends on each other, and therefor partner based relations are more common, in order to increase values together.

\section{A. Conclusions}

This paper is an introduction to the next generation of High Performance Industrial Manufacturing, through the Industry standard 4.0. The fourth Industrial standard is based on advanced Automation and Robotics, sensor based computer technology, interconnected by wireless communication, and supported by BIG Data solutions. In order to succeed with a complex technological integration, we need effective management and excellent Human/Human cooperation. In this light we emphasize the importance of teamwork and Human/Human cooperation and communication. A SUM $\odot$ processes are described in a previous Paper "High Performance Innovative teams (IWAMA 2010), and will be increasingly important in the future. This paper also focuses on the new industrial standard in relation to OEE (Overall Equipment Effectiveness), Predictive Maintenance and total performance 
related to all equipment in the industrial factory processes. We have underlined the importance of using different methods of improvement in order to increase performance.

OEE is a well-known standardized tool for performance measurement throughout the industry. In order to utilize data systems as ERP (Enterprise Resource Planning) and PLM (engineering systems), they must be integrated with Business systems. Management normally acts on the bases of facts and financial performance. In most companies increased profit is the overall goal. Future industrial management systems aims for a fully integrated and automated data flow based on virtual reality (VR) and advanced sensor technology. Increased use of digital systems enables quicker and better decisions, as well as input for Maintenance systems, and Performance data (OEE). Finally, it is expected that next generation for measuring the hidden factory will be Profit Loss Indicators (PLI's).

\section{REFERENCES}

[1] Levitt, J., Lean Maintenance. New York; Industrial Press. ISBN 978-08311-3352-8, 2008.

[2] Bergman, B. and Klefsjö, B., Quality from Customer Needs to Customer Satisfaction. Lund, ISBN 91-44-46331-6, 1994.

[3] Collins, J., Good to Great, Harper Collins Publishers Inc. New York, 2001.

[4] Aune, A., Kvalitetsdrevet ledelse, kvalitetsstyrte bedrifter. Ad notam, ISBN 978-82-417-1123-7, 2000.

[5] Sandengen, O. C., Strategic development and improvement through collaboration and involvement of team members. SINTEF evaluation of the SUM@-model, ISBN 82-595-7856-5, 1994.

[6] OEE Coach.com.

[7] R. Keith Mobley. An introduction to Predictive Maintenance, ISBN 07506-7531-4.

[8] Kagermann, H., Wahlster, W., and Helbig J., Recommendations for implementing the strategic initiative INDUSTRIE 4.0. 2013.

[9] McKinsey\&Company, Industry 4.0 - How to navigate digitization of the manufacturing sector. 2015.

[10] CEN, NS-EN 13306: Maintenance - Maintenance terminology. 2010.

[11] Lee, J., B. Bagheri, and H. A. Kao: A Cyber-Physical Systems architecture for Industry 4.0-based manufacturing systems. Manufacturing Letters, 2015. 3: p. 18-23.

[12] Wang, J. et al.: A new paradigm of cloud-based predictive maintenance for intelligent manufacturing. Journal of Intelligent Manufacturing, 2015: p. 1-13.

[13] Sandengen, O. C., Estensen, L., Schjølberg, P.: High Performance Manufacturing - The SUM ${ }^{\mathrm{TM}}$ Concept, Beyond LEAN II, IWAMA 2012.

[14] Boston Consulting Group, bcg.com, Industry 4.0.

[15] Experton Group AG, Munich, Germany, Arnold Vogt, Dr. Henning Dransfeld, Dr. Michael Weiß and Holm Landrock.

[16] Dr.ing Gaute Knutstad, SINTEF Teknologi \& Samfunn, Teknologiledelse. Trondheim. Norway

[17] Collins, Jim, From Good to Great, ISBN 978-0-06-662099-2.

[18] Rødseth, H., Skarlo T., and Schjølberg P.: Profit loss indicator - A novel maintenance indicator applied for integrated planning. Advances in Manufacturing, 2015. 3(2): p. 139-150.
[19] Rødseth, H., P. Schjølberg, and L.T. Larsen, Industrie 4.0 - A new trend in predictive maintenance and maintenance management, in EuroMaintenance 2016. 2016: Greece.

[20] Herman, M., Pentek T., and Otto B.: Design Principles for Industrie 4.0 Scenarios: A Litterature Review, in Working Paper. 2015, Technische Universität Dortmund \& Audi Stiftungslehrstuhl Supply Net Order Management. 